\title{
FUNCTIONAL DIVERSITY AS A METHODOLOGY TO RETHINK HOUSING NEIGHBOURHOODS
}

\author{
A. Virtudes \\ CIAUD, Research Centre of Architecture, Urbanism and Design, University of Lisbon \\ (PORTUGAL)
}

\begin{abstract}
There are many housing neighbourhoods with no functional diversity, where dwellings are the only function of the buildings. Their inhabitants are out during the day, going to their working places and are coming back only in the evening. Therefore, these mono-functional neighbourhoods, at the suburban parts of the cities, present several problematic aspects, such as in security terms. Consequently, good quality requirements of urban life, are difficult to keep. This paper aims to present the results of an urban project, on behalf on the urban planning subject, at the Architecture studies.
\end{abstract}

The case study area is a peripheral neighbourhood, on the outskirts of the Portuguese city of Covilhã, in the Interior region of the country, near to the border with Spain.

The presented solutions are focused on the urban continuity as the main feature to be development regarding the urban fabric, based on the functional diversity of the place. They are proposing new green spaces, new squares as meeting public spaces, cycling paths and pedestrian sidewalks with greenery. The low density of buildings is an option in order to keep the local identity in architectural and cultural terms, and sustainable urban environments, where people can meet each other, stay together and organize events for all community

Keywords: Functional diversity, housing neighbourhoods, sustainable urban environment, low density buildings.

\section{INTRODUCTION}

The urban studies programmes, regarding the higher education level, such as on behalf of the master degree in architecture, are followed by international students during their educational exchange experiences. Such as other countries, in Portugal every academic year there are students coming from different European countries and from Portuguese speaking countries, such as Brazil, Angola or East Timor to improve their skills in the urban planning domain, learning with the Portuguese framework.

During the academic year of 2018/2019, a group of students were called to join a team work based on the analysis of an urban area, at the outskirts of the city of Covilhã, called Covelo neighbourhood.

Besides of its localization not far away from Covilhã, this area based on single housing of low density, has several problems such as the weakness of the urban continuity. Therefore, the proposed city projects for Covelo are presenting a set of good practices in order to solve these problems, keeping the contents of existing municipal plans.

There are two municipal plans to Covelo, which are the Municipal Master Plan of Covilhã from 1999 and the Urban Development Plan of Covilhã from 2010. These spatial planning instruments should be followed by every proposal of rehabilitation or urban development around this area.

\section{FEATURES OF A SUBURBAN NEIGHBOURHOOD}

Such as in many other countries, there are different level of urbanization density on Portugal.

The main cities are by the Atlantic sea and by the Mediterranean shore, in the south at the Algarve, a very well known touristic spot. In the Interior of the country, which comprises de half part joining the border with Spain, the urban settlements are less crowded and the urbanization register low levels of density. In fact, considering the 10 million inhabitants of this country, nearly $2 / 3$ of the population as a whole are living in the half part of the territory of the sea cost.

At the Beira Interior region, one of the main cities is Covilhã, where from an old industrial dynamic based on the textile industry, is nowadays a university city with about 8.000 students, many of them 
coming from other European countries, African Portuguese speaking countries such as Angola, Cape Verde Islands, or São Tomé and Prince, and from Brazil among others.

Covelo is a neighbourhood at the suburbs of Covilhã. It is a residential district, away (about 10 minutes driving by car and 40 minutes walking by foot) from the urban fabric of the city.

Despite to the short distance to the city centre, it has no conditions for pedestrians to go, because part of the way has no sidewalks for pedestrians and is along to a national road with heavy traffic including trucks, linking the city to the highway A23 accesses (Figure 1).

The case study area was organized in tree zones (A, B, and C) and each group should present an urban design solution for one of these zones (Figure 2).

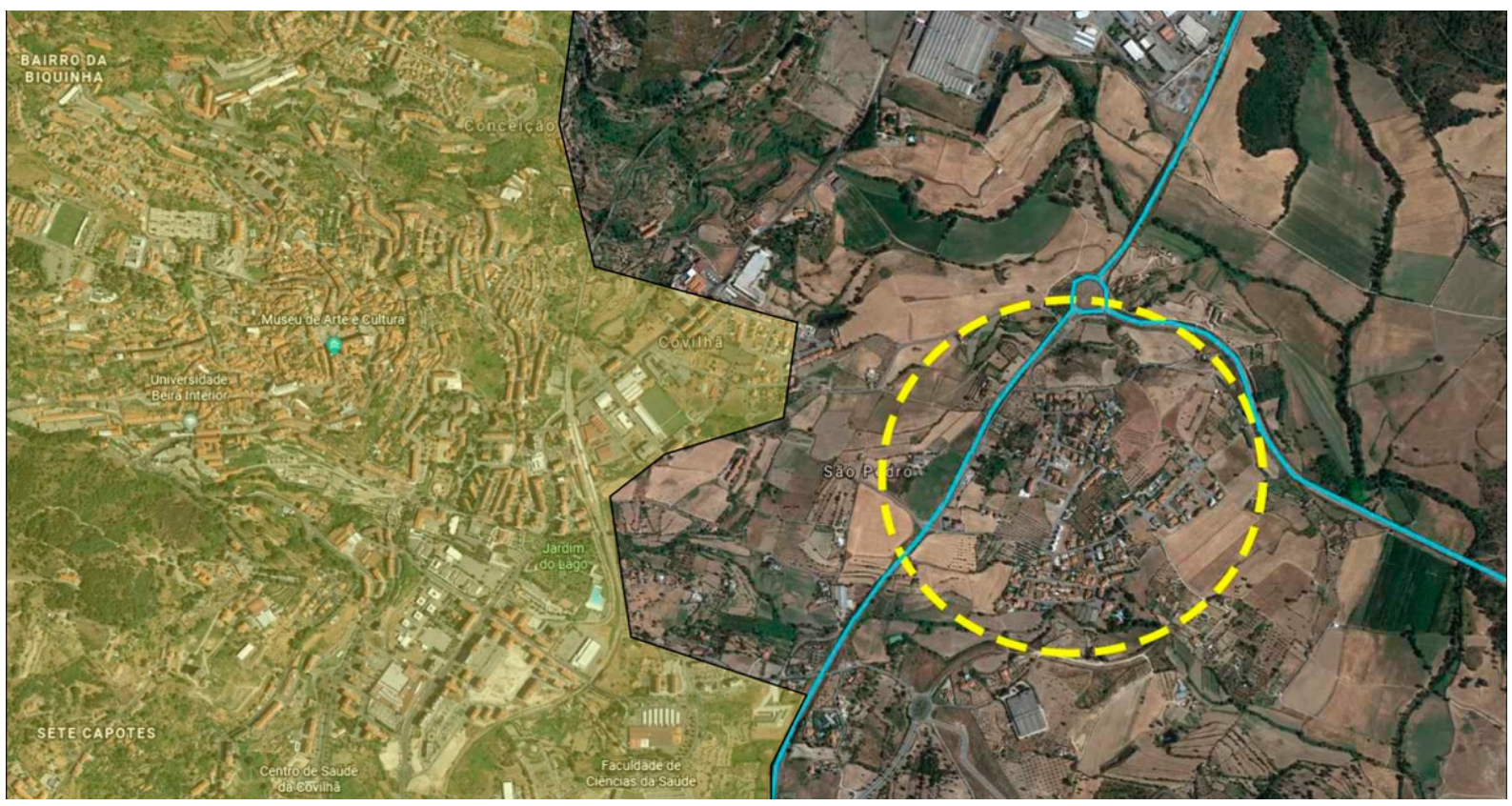

Figure 1: Localization map of the case study area in Covilhã, Portugal (Source: Students group - Cátia Pinto, Eugénio Gerardo, Francisca Verdade and Tatiana Freire - Urban Planning Unit).

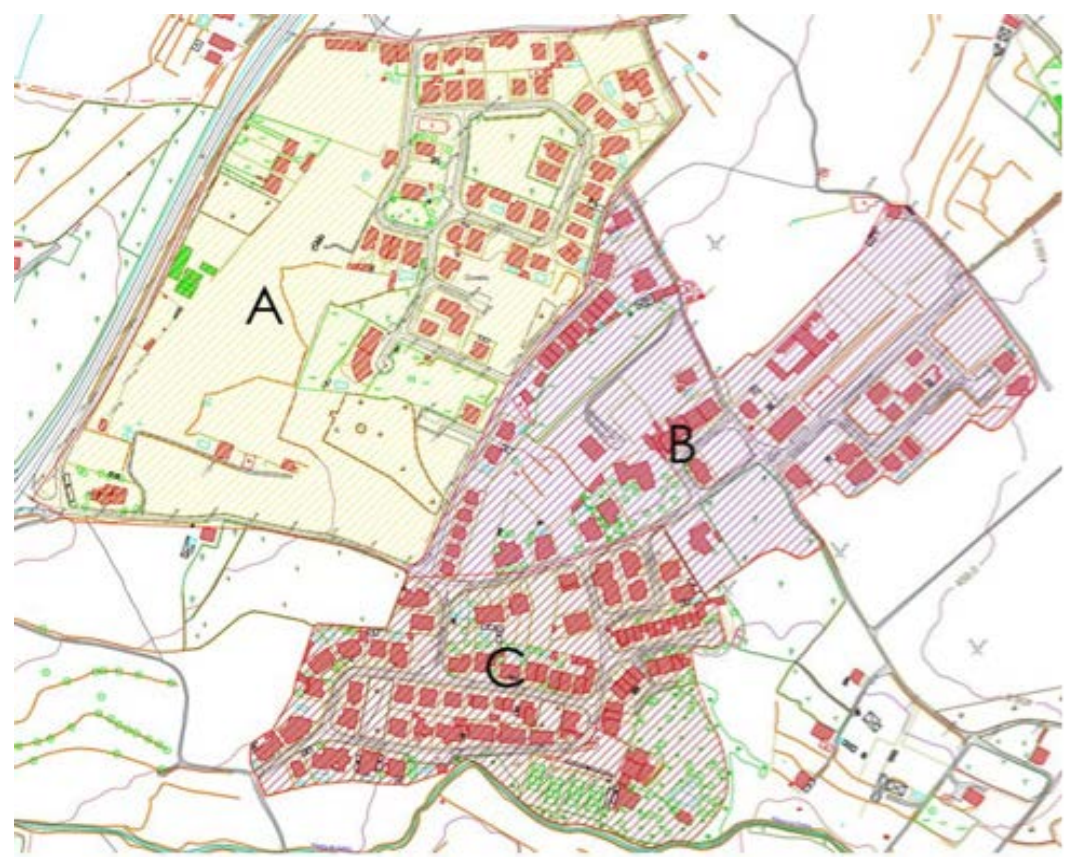

Figure 2: Zones of the case study area in Covilhã, Portugal: A, B, and C (Source: Students group - Gabriela Normanha, Luana Sena, M. Fernanda Sena, and Pedro Sena - Urban Planning Unit). 
All urban spaces have advantages and disadvantages. In fact, cities comprise "all the difficulties inherent to complex systems: a large variety of agents interacting with each other, a large variety of temporal and spatial scales, and a large number of processes that modify the spatial structure and organization of these systems." [1]. In this sense, a strong aspect is that it has public transport access, by bus, to the city centre.

However, the bus timetable doesn't fit with the schools or main jobs schedules. Therefore, the bus can not be considered an alternative mobility choice for the daily commuters, comparing with the car use. This zone has arisen with no planning rules considering the urban fabric as a whole. Its urban growth was based on several urban developments, each one of them according to the size and shape of each previous property, with no continuity among them.

Such as in the history of the city, pre-existing rural property bounds will often influence subsequent urban lines [2] which is the case. This process took place along more than twenty years, and has promoted several problematic aspects which are waiting for solutions.

The urban morphology of the streets of this neighbourhood is predominantly irregular tracing, with a lack of sidewalks and car parking in many cases. Thus, there are some conflicts between pedestrians and cars, such as the cars parking over the sidewalks, being obstacles for pedestrian's mobility.

There are several streets with a dead end, leading to nowhere. This fact is a disadvantage contributing to the weakness of the urban continuity, cutting off the neighbourhood in several parts with no link among them in terms of mobility. An advantage of this area is the low-average density of the urban fabric compared to downtown. The highest buildings have only 4 floor and the majority of them $49 \%$ have 3 floors, followed by the building with two floors, representing about $36 \%$ (Figure 3).

However, there is a lack of public equipment, leisure and services areas, where people can meet, children can play and stay together with their neighbours. The public spaces for neighbours to meet or go for a walk are scarce. Therefore, there is the need of redefine the gardens, meeting points, parks for children and the public spaces in general, in a more dynamic, inhabitable and sustainable manner [3].

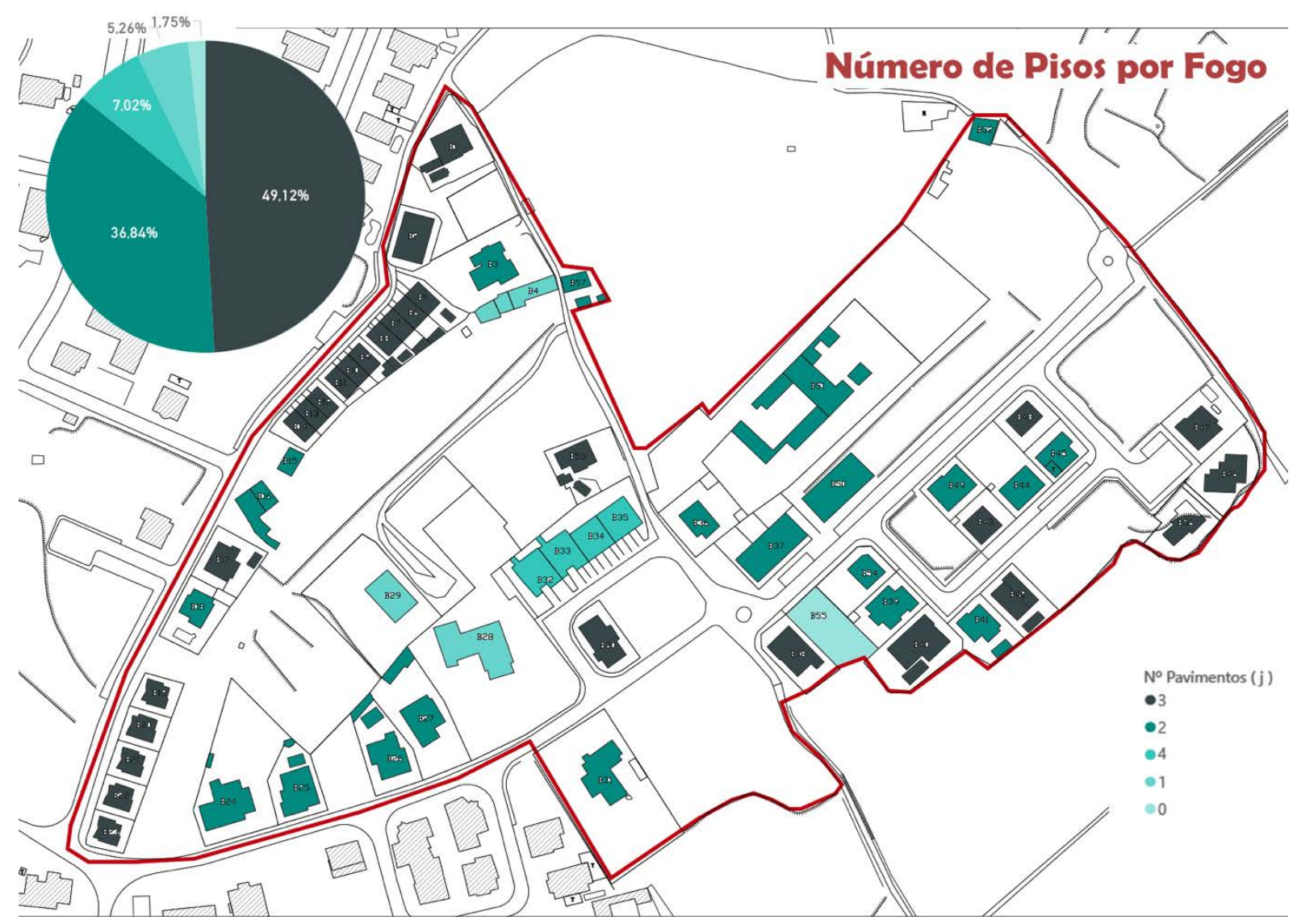

Figure 3: Case study area in Covilhã, Portugal - Zone B: Density map of existing buildings (Source: Students group - Bruno Ferreira, João Calheiros, Marta Nunes, and Paulo Sá - Urban Planning Unit). 
One positive aspect of this housing district based on single houses, is the size of the houses. Nearly $80 \%$ of the houses have more than $300 \mathrm{~m} 3$ (Figure 4). However, there are several urban voids, plots where buildings were never built, wait for an occupation.

These urban voids are giving to the district a poor image in terms of quality. In some cases, they are places where the weeds and small reptiles such as snakes, lizards or spiders are growing. Despite of promoting the biodiversity, such fauna is not always popular nor welcome in housing districts.

A strong aspect of this area is the rural border line of its surroundings. This fact brings to citizens, a feeling of being in contact with nature being not faraway of the city centre. This is one aspect that the city project proposals want to keep, the strong presence of the nature, creating, gardens, urban parks, or proposing the presence of trees along to the streets. In fact, an ecosystem approach to urban planning is a key to sustainable cities [4].

In fact, Jared Green [5] says that one of the aspects that gives people hope for the future, regarding the cities is designing with nature. This feeling is present as well at the plots organization given that the majority of them comprise private yards for gardens where in many cases there is a barbecue or a swimming-pool.

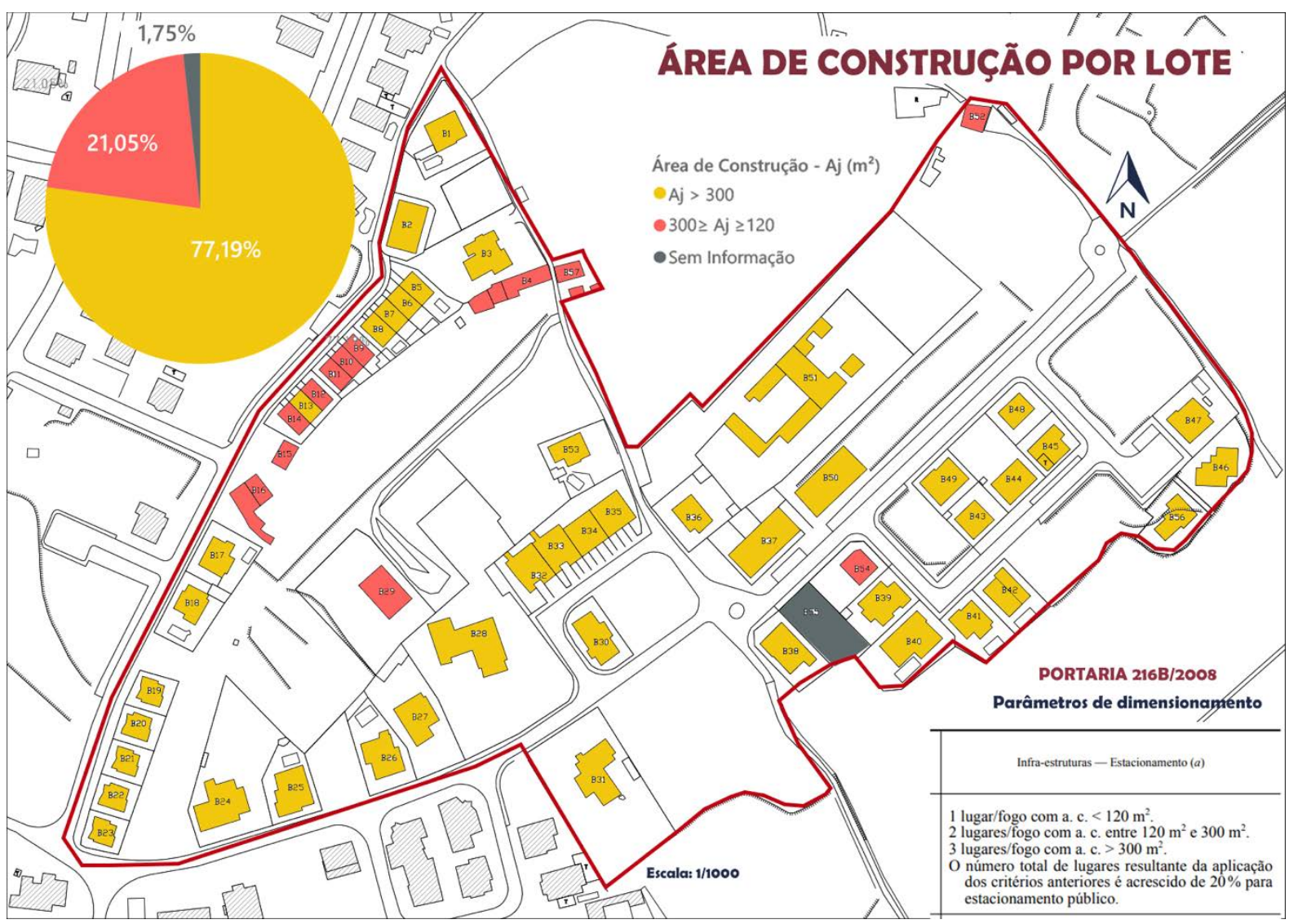

Figure 4: Case study area in Covilhã, Portugal - Zone B: Construction area per plot of existing buildings (Source: Students group - Bruno Ferreira, João Calheiros, Marta Nunes, and Paulo Sá - Urban Planning Unit).

The sizes of the plots are a positive aspect. About $14 \%$ of the existing plots have in between $500 \mathrm{~m} 2$ and $600 \mathrm{~m} 2$, the plots from $200 \mathrm{~m} 2$ to $300 \mathrm{~m} 2$ represent $12 \%$, the plot from $300 \mathrm{~m} 2$ to $400 \mathrm{~m} 2$ represent another $12 \%$ and the plots from $700 \mathrm{~m} 2$ to $800 \mathrm{~m} 2$ represent as well $12 \%$ of the area. The smaller existing plots have less than $200 \mathrm{~m} 2$ and they represent $7 \%$ of the cases (Figure 5).

This is an aspect that the city project proposals want to keep, the high level of sustainability index. In fact, the literature reveals that "the percentage of evapotranspiring surfaces is "two times higher in low density housing than in high density housing" [4]. 


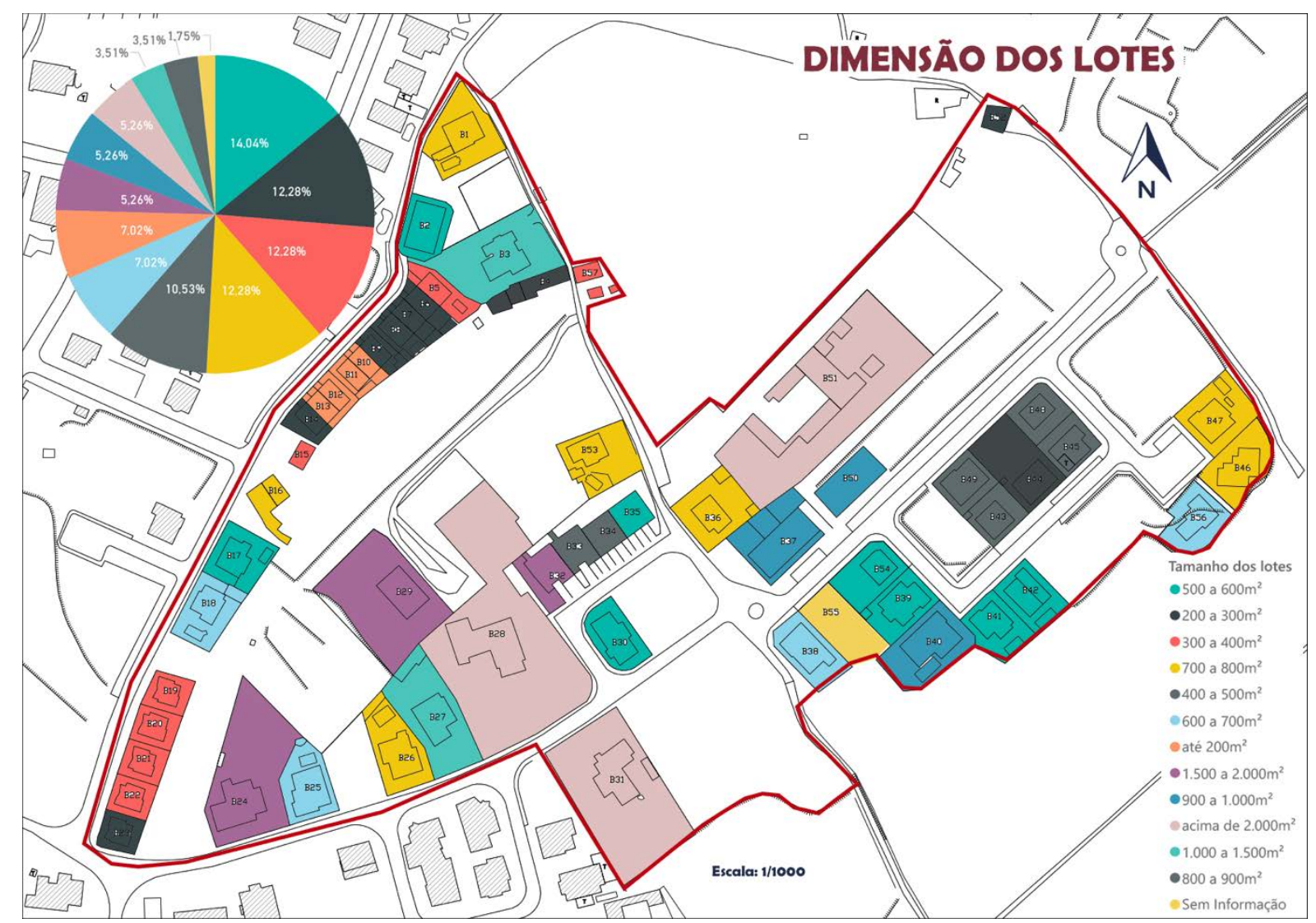

Figure 5: Case study area in Covilhã, Portugal - Zone B: Size of the existing plats map (Source: Students group - Bruno Ferreira, João Calheiros, Marta Nunes and Paulo Sá - Urban Planning Unit).

Another indicator of the urban sustainability of this area is the soil permeability index of the existing plots which can simply be called the sustainability index. It refers to the part of the plot which is left free of buildings and compact pavements. In Covelo most existing plots have a sustainability index above $50 \%$. About $13 \%$ of them have a sustainability index from $70 \%$ to $80 \%$ of the plot surface, $13 \%$ of them are comprised a sustainability index between $60 \%$ and $70 \%$ and another $13 \%$ are between $50 \%$ and $60 \%$.

There are only $8 \%$ of the plots below $50 \%$ of the sustainability index (Figure 6).

The roads network has the following aspects:

It has no continuity given that there are several car lanes with dead end;

In many places there is a lack of sidewalks for pedestrians;

There is a shortage of car parking, with cars parked over the sidewalks;

The urban furniture is put at the wrong places with serious damages for the pedestrian circulation, occupying the its paths;

There are no cycling ways nor green spaces (Figure 7). 


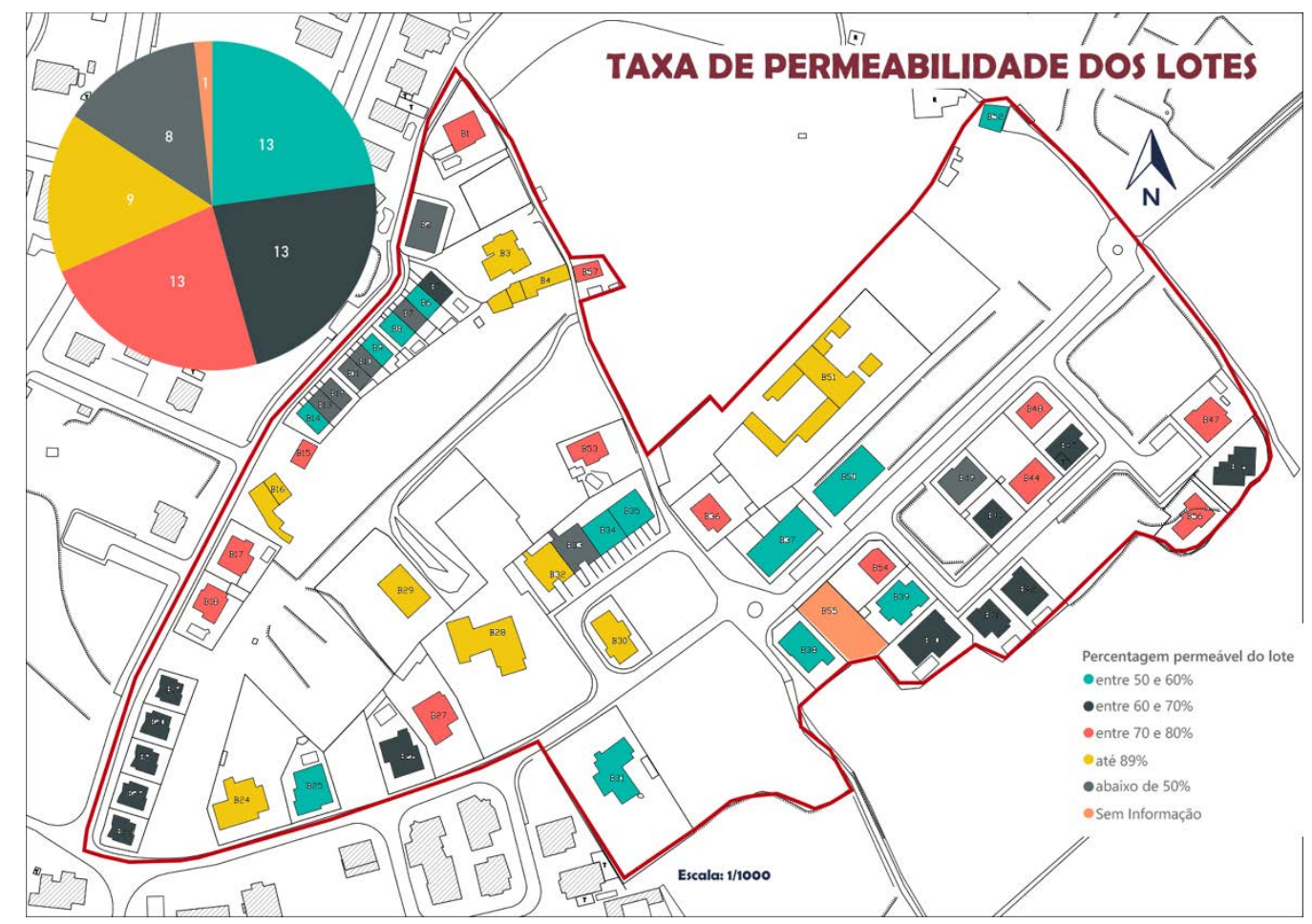

Figure 6: Case study area in Covilhã, Portugal - Zone B: Sustainability index of existing plots (Source: Students group - Bruno Ferreira, João Calheiros, Marta Nunes, and Paulo Sá - Urban Planning Unit).

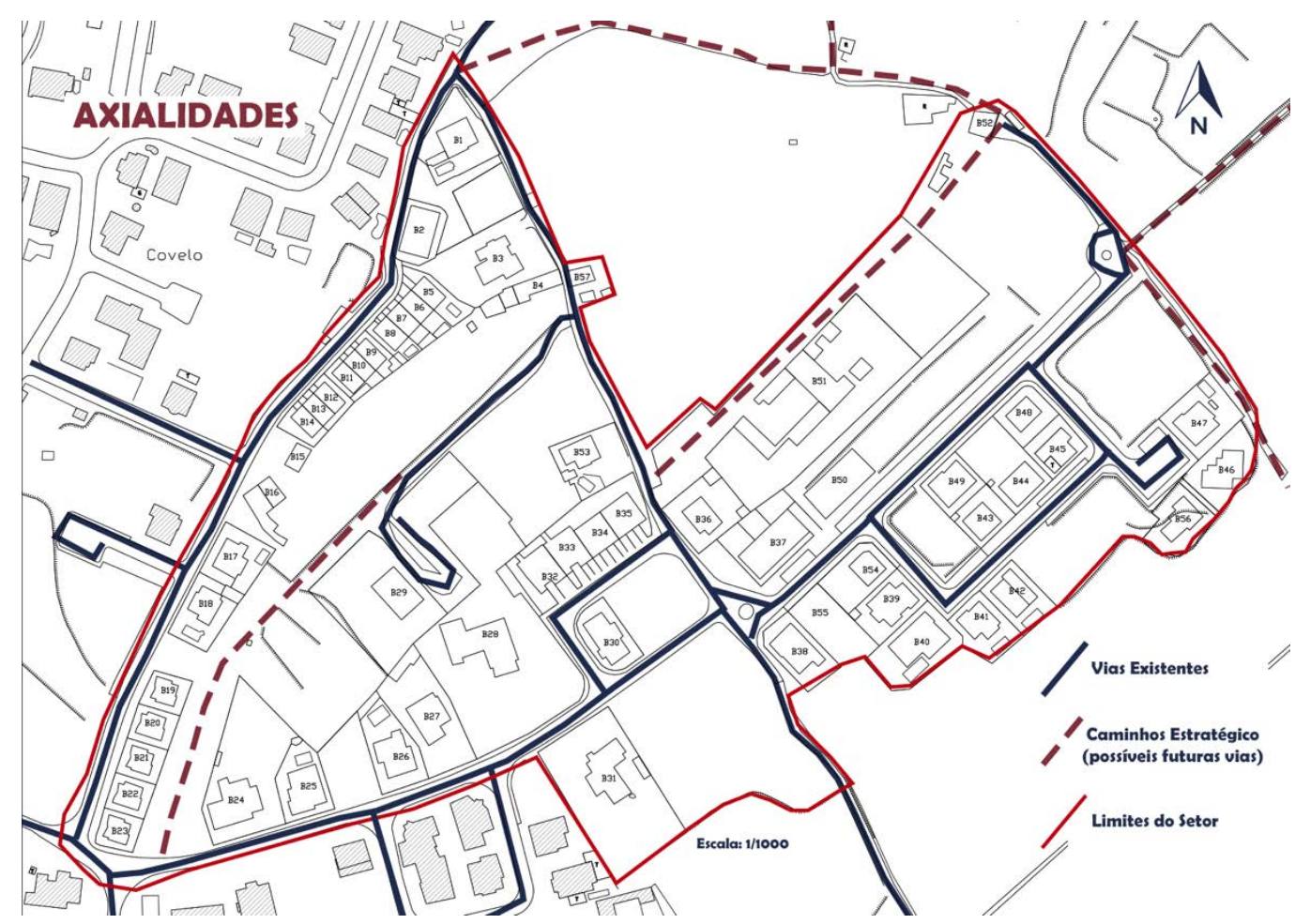

Figure 7: Case study area in Covilhã, Portugal - Zone B: Roads network map (Source: Students group Bruno Ferreira, João Calheiros, Marta Nunes and Paulo Sá - Urban Planning Unit).

\section{PLANNING RULES FOR THE CASE STUDY AREA}

There are two types of planning rules regarding the case study area. The rules which are coming from the national level of the spatial planning system framework and the rules that are coming from the local level of the spatial planning system. In Portugal the latter is the Municipal level of the public realm which is the stronger in term of planning rules. 
The national planning rules are compulsory in every urban development projects all over the country and comprise several aspects such as car parking rules, green spaces rules, or streets measurements. In fact, one of the major challenges of the Urban Planning Unit considering the international students is to deal with the Portuguese planning system networks, its planning instruments, and urbanization rules. In the case study area, Covelo - Covilhã, there are two municipal plans which are compulsory regarding the city project proposals. The first one is the Master Plan of Covilhã coming from 1999 and the second one is the Urban Development Plan of Covilhã coming from 2010.

At the case study area there are no urbanization restriction related with agriculture purposes, or with ecological purposes, which are defined at the Portuguese Municipal Master Plans. According to these Municipal planning instruments, the following urban indicators are compulsory at the case study area, and the city project proposals have to keep them: the maximum number of houses per hectare is 50 , and the maximum construction index is 0,4 .

\section{CONCLUSIONS}

Regarding the academic environment of the university realm, the challenge of having international teams composed by native language speakers and non-native speakers is always a test for scholars. One of the strategies towards the integration of international students is having team composed by pupils with different backgrounds, coming from different higher education systems, countries and experiences, working together and following the same goal.

At the domain of urban planning subjects, such as in the Degree in Architecture, the referred challenge has a particular aspect which is to transfer for international students, knowledge about the planning rules, instruments and system networks of the receiving institution. In Portuguese university, the international students are mainly coming from Portuguese speaking countries, from Africa, or Brazil, and from other European countries.

As these papers aimed to show, the researches focused on the analysis of urban areas, such as suburban neighbourhoods follow several methodological steps, comprising not only a diagnosis of the urbanistic features, but also the need of knowing the spatial planning rules which are compulsory to follow.

\section{ACKNOWLEDGEMENTS}

This work is supported with Portuguese national funds by FCT - Foundation for Science and Technology within the CIAUD, Research Centre of Architecture, Urbanism and Design, University of Lisbon.

\section{REFERENCES}

[1] M. Barthelemy, "Modeling Cities", C. R. Physique (2019). DOI: org/10.1016/j.crhy.2019.05.005.

[2] S. Kostof, The City Shaped: Urban Patterns and Meanings Through History, London, Thames \& Hudson, 1991.

[3] J. M. Minguet, (editor), Sustainable Urban Landscapes, Barcelona, Instituto Monsa de Ediciones, Barcelona, 2008.

[4] J. Niemela, (editor-in-chief), Urban Ecology, Patterns, Processes, and Applications, Oxford University Press, 2011.

[5] J. Green, (2015), Designed for the Future: 80 Practical Ideas for a Sustainable World, New York, Princeton Architectural Press, 2015. 